Journal of Social Sciences 4 (2): 123-127, 2008

ISSN 1549-3652

(C) 2008 Science Publications

\title{
The Use of Mobile Phones by Elderly: A Study in Malaysia Perspectives
}

\author{
Mohd Hairul Nizam Md. Nasir, Hazrina Hassan and Nazean Jomhari \\ Department of Software Engineering, Faculty of Computer Science and Information Technology, \\ University of Malaya, 50603 Kuala Lumpur, Malaysia
}

\begin{abstract}
Mobile phone has become essential part of personal and business life crosses all age and gender boundaries. The of mobile phone usage can potentially play a significant role in assisting older people in many ways especially in terms of maintaining social relationship, providing sense of safety and accessibility. However, older people seem to be the neglected user group in the design of mobile phone devices and services. Hence, this paper attempts to report the issues which are related to the design of mobile devices and services for the elderly aged 56 years old and above specifically in Malaysias context. The findings can be served as a reference to the mobile manufacturer and service provider to put into account during designing mobile devices and services for older people. This research used a survey instrument to gather data from older people across all states in Malaysia with the total of 176 of them responded. The questionnaires were mainly distributed to older person who directly use mobile phones in their daily routines.
\end{abstract}

Key words: Elderly, mobile phone usage, older adults, questionnaire

\section{INTRODUCTION}

The recent growth of mobile phone use is a phenomenon that crosses all age and gender boundaries. More than just the latest electronic gadget, mobile phone has become integral parts of our business and personal lives. According to the Handphone User Survey, 2005 by Malaysian Communication and Multimedia Commission, thirteen percentages of people aged below 20 years old owned a mobile phone. Nearly $80 \%$ of people living in the Malaysia between the ages of 20 and 49 owned or used a mobile phone. The ownership percentages of people in higher age brackets are slightly lower. The ownership drops drastically to $8.7 \%$ for people 50 years old and above.

Elderly people seem to have a neglected user group in design of mobile devices and services, although the requirements to create well functioning solution for them are very well known. People over the age of 60 use mobile phones for very limited purposes, such as for calling or $\mathrm{sms}^{[1]}$ in emergency situations ${ }^{[2]}$. The use of Short Messaging Service to access customers through their handheld devices is gaining popularity, making the mobile phone the ultimate medium for oneto-one marketing.

Most complaint are related to displays that are too small and difficult to see, buttons and characters that are too small causing them to push wrong numbers frequently. They also avoid using more complex function, non user-friendly menu arrangement and unclear instruction on how to find and use a certain function and services that are too expensive. Ease of use and actual need of the services are important criteria. The elderly are ready to begin using the services as long as they truly facilitate independent living $^{[3]}$.

Mobile phones can potentially play an important role in helping older people in many ways if the problems related to the use of mobile phones can be solved, especially for maintaining and developing social relationship. Mobile technology allows not only ubiquitous communications but also anytime access to some services that are vital for elderly peoples security and autonomy ${ }^{[4]}$. They provide a sense of security and safety for eldest as they can be reached practically anytime and anywhere.

Unfortunately, there were not many studies that involved older persons in the development phase of mobile phones (an exception is universal design activities reported by Fujitsu-although the oldest participant was only 60 years old of age ${ }^{[5]}$ ). Past studies show that when asked, the older people were quite creative, innovative and able to come out with futuristic and out-of-the-box idea such as health

Corresponding Author: Mohd Hairul Nizam M. Nasir, Faculty of Computer Science and Information Technology,

University of Malaya, Lembah Pantai, 50603, Kuala Lumpur, Malaysia

Tel: +603-79676340, Fax: +603-21784965 
monitor function and security-bracelet function that can send calls to help.

\section{MATERIALS AND METHODS}

The main objective of this research is to replicate the study performed by Sri Kurniawan et $a l^{[6]}$ in a different country. Simultaneously, the focus will be on verifying the relevance of the identified design issues as well as comparing the similarities and difference between the studies. Essentially, we perform the initial literature review on mobile phone usage among older peoples, looking at the broader context of mobile devices and services issues, current problems highlighted in various previous studies. In order to acquire the overall picture of mobile phone usage by older peoples, some subjects related to the mobile phone usage, problems, perceived benefits and features are reviewed. Mostly, the review is focused comprehensively on the past published studies on mobile phone usage and design issues. All the information above is collected using on-line search via the internet specifically on the online databases namely ACM, IEEE, technical reports, academic textbooks, magazines, online articles and others.

Secondly, we get the original questionnaires based on the research ${ }^{[6]}$ and then the questionnaires were distributed to older peoples who are directly using a mobile phone in their daily routines across 14 states in Malaysia. From the questionnaires that have been distributed, 176 older peoples taking part in this survey. The result of this survey will be presented in the Fig. 3, meanwhile based on the data that have been analyzed, the desirable and unwanted features will be reported accordingly as demonstrated in Table 1.

\section{DEMOGRAPHY INFORMATION}

The demography information has been organized in the first section in the questionnaires which comprises several multiple choice questions. Only the basic attribute of respondents covered in this section such as gender, age and current mobile used. Exactly 176 respondents participated in the survey. Fortunately, the survey was dominated by man respondents $(60 \%)$. Based on Fig. 1, the majority of respondents were 5660 years old $(56 \%)$, had used mobile phones for more than 2 years $(60 \%)$.

\section{USAGE PATTERNS}

As illustrated in Fig. 2, 105 respondents recorded were use mobile phones more than 2 years and only 8
Table 1: The Influence Level of Response the Features in the Mobile Phone

\begin{tabular}{llllll}
\hline \multicolumn{7}{c}{ Influence level of response } \\
& 1 & 2 & 3 & 4 & 5 \\
\hline QE1 & 5 & 13 & 75 & 61 & 16 \\
QE2 & 4 & 17 & 97 & 41 & 11 \\
QE3 & 0 & 1 & 21 & 55 & 93 \\
QE4 & 1 & 82 & 49 & 49 & 28 \\
QE5 & 1 & 2 & 30 & 80 & 57 \\
QE6 & 1 & 1 & 42 & 58 & 68 \\
QE7 & 9 & 11 & 83 & 50 & 17 \\
\hline
\end{tabular}

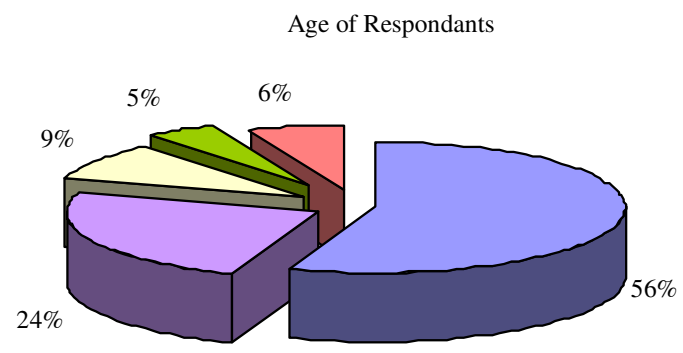

$\square$ between $56-60$ years old $\square$ between $61-65$ years old $\square$ between $71-75$ yearsold $\square$ between $66-70$ years old

Fig. 1: Number of respondents according to age

Usage Frequency of Mobile Phone by Older Peoples

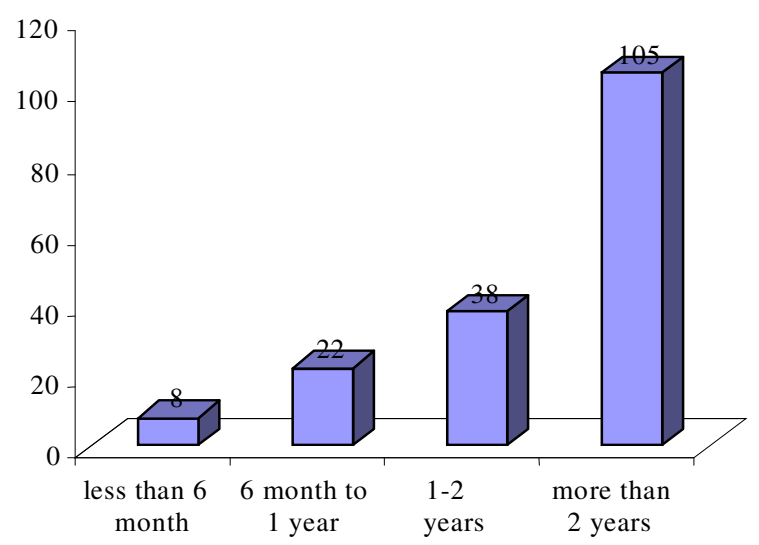

Fig. 2: The usage frequency of mobile phone by older peoples

respondents noted that they were used less than 6 month. More than half used their phones daily. According to the questionnaire result, they were almost pay on prepaid scheme. On an average month, $40 \%$ paid RM 30-RM70, 37 \% paid less than RM30 and 23 $\%$ paid more than RM70. Around half of respondents frequently used 4-5 functions out of the eleven functions listed. The first two reasons for using mobile phones were for emergency $(60 \%)$ followed by for a 
casual conversation (48\%). They were most often called their children/grandchildren $(64 \%)$ or friends $(50.5 \%)$.

\section{THE DESIGN}

The most important aspect of the design process is to provide the user with the real user context. For mobile phones this means users need to be able to touch the buttons and see software that feels like it is actually working $^{[7]}$.

Most of respondents realize how important mobile phone to their daily lives. Because of this and because they use mobile phone on a daily basis, they were increasingly interested in personalizing their phones so that they have the design and functionality that they were seeking. Although there are some people who will spend a fortune to get the phone that has the exact features they desire, most of respondents still leave the comments and suggestions via the questionnaire, the current problem they were faced daily.

The respondents were instructed to rate each feature either it is tolerable annoying or stressful based on their experience with various aspect of their mobile phones. Around half of respondents marked tolerable for almost all features and very few respondents considered using any features as annoying or stressful $(5 \%)$.

The following were highlight some of the major problems when using the current phone the respondent found and explores some of the reasons noted:

- Buttons: Small, rubbery buttons were dislike

- Reason: They preferred metallic buttons, which clicked when pressed

- Menus: Complex and too many options those are often unnecessary

- Reason: Older users require longer time to think of what to type or to choose from many options

- Functions: That are difficult to understand, complicated and thus impossible to recall

- Reason: These are the functions that should be hardwired to particular buttons

- Display: One that can display large text and whose screen backlight does not turn off when idling

- Reason: Older persons require extra cognitive processing time when dialing number or write text

- Shape/size: That is too small to hold and read easily. Size bulky

- Reason: Cant grab and held uncomfortably

- Colours: Although color was not as important as other features, some older persons disliked brightly colored phones for fear of being too visible. Reason: Easier to spot in a crowded handbag

\section{RESULTS AND DISCUSSION}

Technological development is already being shaped to accommodate elderly users special requirements and many devices and services are on offer to help them cope with everyday activities ${ }^{[3]}$ generally within the home. However, as technology becomes increasingly sophisticated, the idea of mobile services to support the elderly in a wide variety of situations is becoming more feasible and attractive as a tool to increase the autonomy of elderly people ${ }^{[4]}$.

The arrival of mobile phone has revolutionized the telecommunication. No other invention has created an impact as this device. By taking care of the methods of the usage, the user can conveniently protect the device. No more comfort but necessity. In order to keep track of all of these features, they were suggest to move an old phone design to a new one, senior-friendly design that help they stay organized and making mobile phones more useful. In this analysis, the 5-point Likertlike scales is used to capture the view of respondents when they were asked to rate. These are:

- It is cheaper to use mobile phone than to use landline phone

- I have more friends after having a mobile phone

- I feel more confident to go out by myself after having a mobile phone

- I am not afraid of getting lost after having a mobile phone

- I know I can always call somebody on my mobile phone when I am in trouble

- I feel safer to be alone because of my mobile phone

- It is fun to use mobile phone

Figure 3 illustrates the distribution of ratings. The most positively respondent statement was the fifth statement, was one that suggests that mobile phones allow older people to call somebody when they were in trouble (90\% respondents agreed or strongly agreed to this statement). The most negative response that using mobile phone because of cheap. (39 respondents).

To understand mobile phone users opinions on less common functions, a list proposed by the focus group was created for the respondents to rate as must be removed (1), good if removed (2), can live without (3), good to have (4) and must have (5). The respondents tended not to choose the must be removed option. Although video and camera is a hot commodity on the 


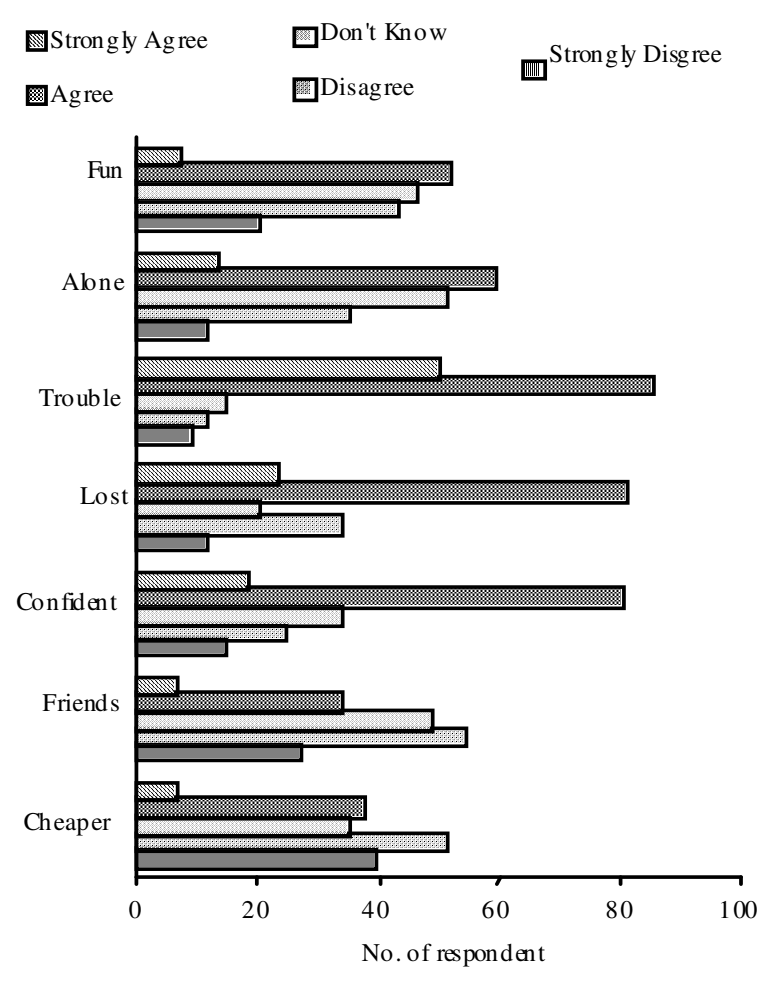

Fig. 3: Respondent's view on the roles of mobile phone use in daily life

Internet right now and the interest in mobile video is growing by the minute and but sometimes it just arent important enough for older user. Some respondents quickly pointed that camera and video phones must be removed. They thought that camera phones were the most dangerous invention of the 21 st century as it encouraged people to do evil things such as bullying. The majority checked can live without or good to have. All these top 3 functions are classified under good to have or must have factor were address book, text messaging and alarm clock, as summarized in details in Table 1. The results gained in this research are not much different with the results survey conducted by Kurniawan et al. ${ }^{[2]}$ whereby necessity in today be the guidelines for user to response.

\section{LEGEND}

$\begin{array}{ll}\text { QE1 } & \text { Camera } \\ \text { QE2 } & \text { Video Phone } \\ \text { QE3 } & \text { Address book } \\ \text { QE4 } & \text { Diary } \\ \text { QE5 } & \text { Alarm } \\ \text { QE6 } & \text { Text Messaging } \\ \text { QE7 } & \text { MP3 Player }\end{array}$

\section{CONCLUSION}

This study is an exposure the design issues of mobile devices and services by older peoples in Malaysia. It presents rich data results from literature review and questionnaire methods. The study shows that older persons used and had strong opinions on some advanced features of mobile phones. Although people often underestimate the interest of older persons on mobile technology, it is undeniable that ageingrelated functional decline has some impact on their use of mobile phones.

As a research approaches, questionnaire has been proven in this research to be quite successful in gaining an understanding of how some older persons used mobile phones. The survey findings were able to capture basic requirements of a mobile phone preferred by older persons, prior to design. The research questionnaires were used to highlight analytically several issues that were important for older users.

The survey data confirm the view of the respondents that mobile phones are for emergency, for instance. The survey also indicated that the most important role of mobile phones was to provide assurance to older persons that they could always call somebody when they were in trouble.

The data captured also revealed the preferred physical design of mobile phones for older persons. It is clear from this study that mobile phone design and usage for older persons is not necessarily limited to or based on old style, out-of-date model and supporting only very basic calling functions. And finally, to unwrap to more interesting findings, more extensive statistical analysis is needed which can be customized to older user needs and perceived to be senior-friendly and reliability.

\section{ACKNOWLEDGEMENT}

First and foremost we would like to express our gratitude to almighty that gave us the possibility to complete the research work successfully. Secondly, we would like to forward our deepest thank to my colleagues, lecturers and technical staffs from the Department of Software Engineering for their endless assistance, technical advice and co-operation.

\section{REFERENCES}

1. Turel, O., A. Serenko and N. Bontis, 2007. User acceptance of wireless short messaging services: Deconstructing perceived value. Inform. Manage., 44: 63-73. Doi: 10.1016/j.im.2006.10.005. 
2. Davie, R., C. Panting and T. Charlton, 2004. Science direct-telematics and informatics: Mobile phone ownership and usage among preadolescents. Telemat. Inform., 21: 359-373. doi: 10.1016/j.tele.2004.04.001.

3. Mikkonen, M., S. Väyrynen, V. Ikonen and M.O. Heikkilä, 2002. User and concept studies as tools in developing mobile communication services for the elderly. Personal Ubiquit. Comput., 6: 113-124. Doi: 10.1007/s007790200010.

4. Abascal, J. and A. Civit, 2001. Universal access to mobile telephony as a way to enhance the autonomy of elderly people. In: Proceedings of the 2001 EC/NSF Workshop on Universal Accessibility of Ubiquitous Computing: Providing for the Elderly, May 22-25. Alcácer do Sal, Portugal, doi:10.1145/564526.564551.

5. Irie, T., K. Matsunaga and Y. Nagano, 2005. The UD Phenomenon in Japan: Product innovation through universal design. Universal Design Activities for Mobile Phone: Raku Raku PHONE. Fujitsu Scientific and Technical Journal 41 (1): Special Issue on Universal Design, 78-85. doi:10.1007/978-3-540-73279-2.
6. Kurniawan, S., M. Mahmud and Y. Nughoro, 2006. A study of the use of mobile phones by older persons. CHI 06 Extended Abstracts on Human Factors in Computing Systems, April 22-27. Montréal, Québec, Canada. doi: 10.1145/1125451.1125641.

7. Ballagas, R., M. Ringel, M. Stone and J. Borchers, 2003. Istuff: A physical user interface toolkit for ubiquitous computing environments. Proceedings of the SIGCHI conference on human factors in computing systems, April 05-10. Association for Computing Machinery, New York, USA. doi: 10.1145/642611.642705. 